\title{
Fatores que contribuem para o desmame precoce: uma revisão integrativa
}

\author{
Factors that contribute to early weaning: an integrative review \\ Factores que contribuyen al destete temprano: una revisión integrativa
}

Recebido: 15/12/2020 | Revisado: 17/12/2020 | Aceito: 21/12/2020 | Publicado: 01/01/2021

\author{
Angela Lúcia Silva do Nascimento \\ ORCID: https://orcid.org/0000-0003-4109-0308 \\ Centro Universitário Tiradentes, Brasil \\ E-mail: luciacloves@hotmail.com \\ João Lourenço dos Santos Neto \\ ORCID: https://orcid.org/0000-0001-6681-7206 \\ Centro Universitário Tiradentes, Brasil \\ E-mail: joaoneto97@outlook.com \\ Ana Paula Rebelo Aquino Rodrigues \\ ORCID: https://orcid.org/0000-0001-5174-5238 \\ Centro Universitário Tiradentes, Brasil \\ E-mail: apaularebelo@ hotmail.com \\ Layne Darline Santos Medeiros \\ ORCID: https://orcid.org/0000-0002-5306-4628 \\ Centro Universitário Tiradentes, Brasil \\ E-mail:1.darline@ hotmail.com \\ Givânya Bezerra de Melo \\ ORCID: https://orcid.org/0000-0001-8951-4881 \\ Centro Universitário Tiradentes, Brasil \\ E-mail: givanya@gmail.com
}

\begin{abstract}
Resumo
Objetivo: Este estudo teve como objetivo descrever os fatores que contribuem para o desmame precoce. Métodos: Tratase de uma revisão integrativa. Foram realizadas buscas na literatura latino-americana e do Caribe em Ciências da Saúde (LILACS), no Medical Literature Analysis and Retrievel System Online (MEDLINE) e na Base de Dados em Enfermagem (BDENF), com estratégias de buscas que combinaram os descritores aleitamento materno, desmame, período pós-parto e cuidado pré-natal. Nove artigos compuseram a amostra final. Resultados: A percepção de leite insuficiente/fraco foi o motivo mais frequente, sendo apontado em 66,66\% das publicações, seguido de 33,33\% de intercorrências mamárias e de 33,33\% de pega incorreta. Conclusão: A identificação desses fatores que levam ao desmame precoce é imprescindível para a promoção de intervenções mais efetivas a fim de minimizar os empecilhos que levam ao desmame precoce. É fundamental que os profissionais de saúde e gestores possam discutir esses fatores de forma ampliada e tracem estratégias favoráveis à melhora da adesão ao AME.
\end{abstract}

Palavras-chave: Aleitamento materno; Cuidado pré-natal; Desmame; Período pós-parto.

\begin{abstract}
Objective: This study aimed to describe the factors that contribute to early weaning. Methods: this is an integrative review. Searches were conducted in Latin American and Caribbean Literature in Health Sciences (LILACS), Medical Literature Analysis and Retrievel System Online (MEDLINE) and in the Nursing Database (BDENF), with search strategies that combined the keywords: maternal breastfeeding, weaning, postpartum period and prenatal care. Nine articles made up the final sample. Results: The perception of insufficient/weak milk was the most frequent reason, being mentioned in $66.66 \%$ of publications, followed by $33.33 \%$ of breast complications and $33.33 \%$ of incorrect breastfeeding latch. Conclusion: The identification of these factors that lead to early weaning is essential to promote more effective interventions in order to minimize the obstacles that lead to early weaning. It is essential that health professionals and managers can discuss these factors in a broader way and outline strategies favorable to improving adherence to AME.
\end{abstract}

Keywords: Breastfeeding; Prenatal care; Weaning; Postpartum period.

\section{Resumen}

Objetivo: Este estudio tuvo como objetivo describir los factores que contribuyen al destete temprano. Métodos: esta es una revisión integradora. Se realizaron búsquedas en Literatura Latinoamericana y del Caribe en Ciencias de la Salud (LILACS), Sistema de Análisis y Recuperación de Literatura Médica en Línea (MEDLINE) y en la Base de Datos de Enfermería (BDENF) con estrategias de búsqueda que combinaban las palabras clave: lactancia materna materna, destete, puerperio, atención prenatal. Nueve artículos conformaron la muestra final. Resultados: La percepción de leche insuficiente / débil fue el motivo más frecuente, siendo mencionado en el 66,66\% de las publicaciones, seguido del 
33,33\% de complicaciones mamarias y el 33,33\% de manejo incorrecto. Conclusión: La identificación de estos factores que conducen al destete temprano es fundamental para promover intervenciones más efectivas con el fin de minimizar los obstáculos que conducen al destete temprano. Es fundamental que los profesionales y gestores de la salud puedan discutir estos factores de una manera más amplia y delinear estrategias favorables para mejorar la adherencia a la LME.

Palabras clave: Lactancia materna; Atención prenatal; Destete; Posparto.

\section{Introdução}

No Brasil, verifica-se que, embora a maioria das mulheres inicie o aleitamento materno, mais da metade das crianças já não se encontram em amamentação exclusiva no primeiro mês de vida. Segundo o Fundo das Nações Unidas para a Infância (UNICEF) e a Organização Mundial da Saúde (OMS), nenhum país do mundo atende plenamente aos padrões adequados da amamentação, incluindo o Brasil, que tem uma taxa de apenas $38,6 \%$ de crianças amamentadas exclusivamente até o $6^{\circ}$ mês de vida (OPAS, 2018).

Um estudo de Sousa e colaboradores (2015) revela que anualmente há 10 milhões de óbitos infantis no mundo; 38\% desses ocorrem nas primeiras quatro semanas de vida. Os óbitos podem ter associação ao desmame ainda numa fase muita prematura, uma vez que a amamentação é uma fonte de intervenção para doenças infecciosas e contribui para diminuir os riscos de mortalidade infantil.

A OMS recomenda que o Aleitamento Materno Exclusivo (AME) aconteça até os primeiros seis meses de vida do recém-nascido, sem a inserção de leite de outras fontes, fórmulas ou outros alimentos sólidos e líquidos na alimentação do lactente. Essa prática ainda deve ser incentivada após o $6^{\circ}$ mês de vida. A partir de então, com a oferta de refeições à criança, pode estender-se até dois anos de idade ou mais (Brasil, 2015).

Estudos apontam os inúmeros benefícios e eficácia do aleitamento materno (Silva; Tonon, 2020). Entre esses, destacamse a proteção à saúde da mulher e da criança, traduzida na redução da mortalidade infantil, a desnutrição, a obesidade e a prevenção do câncer de mama. Esse fenômeno é influenciado por múltiplos fatores e constitui um desafio para as intervenções de profissionais de saúde com o intuito de prolongar o AME (Almeida; Luz; Ued, 2015).

Entre os motivos do desmame precoce estão as inúmeras dificuldades encontradas pela mãe no ato de amamentar (Amaral et al., 2015). Algavares, Julião e Costa (2015) associam o desmame precoce à falta de conhecimento das mães sobre a importância do leite materno, aos mitos e crenças sobre a prática, à baixa escolaridade e ao reduzido número de consultas no pré-natal. É imprescindível intensificar as ações educativas a fim de intervir nos fatores que dificultam o aleitamento materno.

Araújo e colaboradores (2013) acrescentam que a baixa idade materna também pode ser um fator que contribui para o desmame precoce; as maiores prevalências são encontradas exatamente entre mães adolescentes. Nesse contexto, ressalta-se a importância dos profissionais de saúde, em especial o enfermeiro, sobre a prática do aleitamento materno exclusivo, uma vez que este profissional possui conhecimento técnico-científico para instruir a essa mulher e seus familiares (Amaral et. al., 2015).

A qualidade do pré-natal, prática que deve contar com a participação ativa do enfermeiro, tem um forte poder de influenciar na decisão da mulher de amamentar ou não. Durante as consultas devem ocorrer os primeiros incentivos ao aleitamento materno, as devidas orientações acerca da importância em amamentar nas primeiras horas de vida e o aconselhamento sobre as dificuldades que possam vir a comprometer a prática da amamentação (Algavares; Julião; Costa, 2015).

Algavares e colaboradores (2015) anotam que tanto as mulheres que já receberam orientação desde o pré-natal quanto as que já possuem prática na amamentação precisam continuar recebendo incentivo, pois cada gestação, paridade e aleitamento consistem em momentos singulares (Brasil, 2015).

Faz-se necessário reconhecer a complexidade da amamentação, o que exige o envolvimento e a participação efetiva não apenas do profissional enfermeiro, mas de todos que cercam a mulher e de alguma forma podem influenciar nessa prática. 
Recomenda-se que o aleitamento seja desenvolvido de forma conjunta, sobretudo com o apoio do parceiro, para que a mulher se sinta segura na decisão de amamentar o seu bebê (Barbosa et al., 2014).

A participação do genitor no pré-natal é tão necessária quanto à da mãe, por favorecer a melhor interação pai-filho. Ao se reconhecer a importância do envolvimento familiar e da sua efetiva participação no pré-natal, certamente isso favorece que o pai compartilhe os deveres e responsabilidades nos cuidados da mulher e da criança, incluindo o processo de amamentação (Brasil, 2015).

O Ministério da Saúde (2015) revela que as práticas educativas em todos os níveis de atenção ainda se constituem como um ponto de conscientização sobre os males que o desmame precoce pode acarretar na vida do binômio mãe-filho. Compete ao enfermeiro promover ações que visem orientar a nutriz sobre os benefícios da amamentação e os riscos em promover o desmame.

A Organização Pan-Americana de Saúde (2018) observa que os esforços conjuntos dos profissionais de saúde, gestantes e familiares, bem como as políticas públicas existentes, ainda não resultam no aumento esperado da taxa de amamentação exclusiva nos seis primeiros meses de vida. Já a Organização das Nações Unidas (2016) ressalta que a amamentação encontrase entre as metas para alcançar os objetivos de Desenvolvimento Sustentável, achando-se entre os fatores que podem contribuir para a erradicação da pobreza.

Apesar de o leite materno ser considerado o alimento ideal para o recém-nascido, o aleitamento persiste sendo uma tarefa difícil. Muitas puérperas são acometidas por medo, dúvida, insegurança e falta de apoio familiar. Como consequência desse cenário, é muito comum ocorrer o abandono da amamentação exclusiva, com a oferta a crianças de bicos artificiais e leites de fórmulas (Brasil, 2015).

Sabe-se que muitas puérperas interrompem precocemente o aleitamento materno exclusivo. Assim, é de suma importância o desenvolvimento de estudos que identifiquem os fatores envolvidos nessa problemática. Nesse sentido, o presente estudo tem como objetivo identificar na literatura científica os fatores que contribuem para o desmame precoce.

Pretende-se responder à seguinte questão de pesquisa: quais os fatores que contribuem para o desmame precoce?

\section{Metodologia}

Este estudo utilizou o método de revisão integrativa da literatura, visando reunir e sintetizar resultados de pesquisas sobre um determinado tema ou questão, de modo sistemático e ordenado, contribuindo assim para o aprofundamento do tema investigado. Inclui a análise de pesquisas relevantes que dão suporte à tomada de decisão e melhoria na prática em saúde, sobretudo em enfermagem (Souza, Silva, Carvalho, 2010; Sousa et al., 2017).

O desenvolvimento desse método contempla as seis seguintes etapas: $1^{a}$ ) identificação do tema e elaboração da pergunta norteadora; $2^{\mathrm{a}}$ ) busca na literatura com seleção criteriosa; $3^{\circ}$ ) coleta de dados; $4^{\mathrm{a}}$ ) análise crítica dos estudos incluídos; $5^{\mathrm{a}}$ ) discussão dos resultados; e 6 ${ }^{\text {a }}$ ) apresentação da revisão integrativa (Souza, Silva, Carvalho, 2010).

$\mathrm{Na}$ primeira etapa, foi elaborada a seguinte pergunta norteadora: quais os principais fatores que contribuem para o desmame precoce? Na segunda, foram montadas as estratégias de buscas utilizando os seguintes Descritores em Ciências da Saúde (DeCS): aleitamento materno, desmame e período pós-parto, combinados com os operadores booleanos AND e OR. Na terceira etapa, realizaram-se as buscas eletrônicas na literatura latino-americana e do Caribe em Ciências da Saúde (LILACS), no Medical Literature Analysis and Retrievel System Online (MEDLINE) e na Base de Dados em Enfermagem (BDENF).

Foram critérios de inclusão: estudos primários publicados no período de janeiro de 2010 a outubro de 2020, disponíveis na íntegra em português e que tratassem dos fatores que levam ao desmame precoce. 
Quadro 1 - Fluxograma de seleção dos artigos que compõem a amostra final do estudo. Maceió - AL, Brasil, 2020.

\begin{tabular}{|c|c|c|c|c|c|c|c|}
\hline 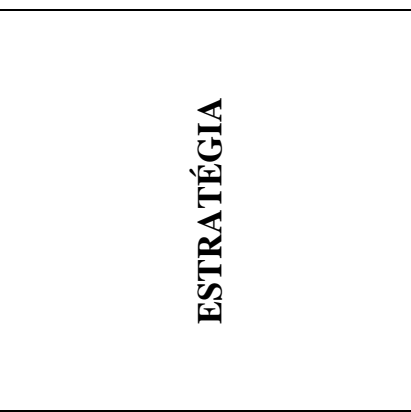 & 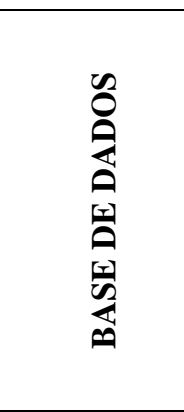 & 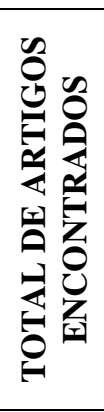 & 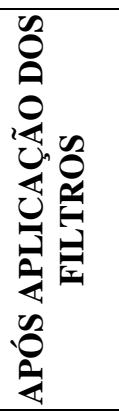 & 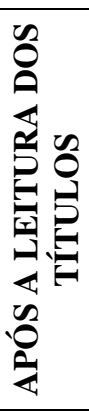 & 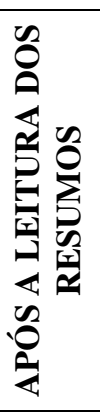 & 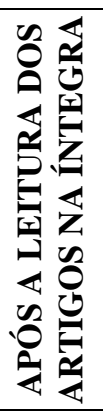 & 起 \\
\hline \multirow{3}{*}{$\begin{array}{c}\text { Aleitamento Materno AND } \\
\text { desmame }\end{array}$} & LILACS & 633 & 183 & 33 & 8 & 5 & 5 \\
\hline & MEDLINE & 1352 & 14 & 5 & 1 & 1 & 1 \\
\hline & BDENF & 178 & 82 & 21 & 8 & 5 & 5 \\
\hline \multirow{3}{*}{$\begin{array}{c}\text { Aleitamento Materno OR } \\
\text { Amamentação AND } \\
\text { desmame OR desmame } \\
\text { precoce }\end{array}$} & LILACS & 4724 & 1.072 & 23 & 9 & 7 & 7 \\
\hline & MEDLINE & 34237 & 231 & 7 & 2 & 2 & 2 \\
\hline & BDENF & 926 & 485 & 4 & 2 & 1 & 1 \\
\hline \multirow{3}{*}{$\begin{array}{l}\text { Aleitamento materno AND } \\
\text { desmame AND puerpério } \\
\text { OR período pós-parto }\end{array}$} & LILACS & 633 & 100 & 16 & 2 & 2 & 2 \\
\hline & MEDLINE & 1352 & 16 & 4 & 0 & 0 & 0 \\
\hline & BDENF & 178 & 82 & 12 & 3 & 2 & 2 \\
\hline \multicolumn{7}{|c|}{ TOTAL DE ARTIGOS ENCONTRADOS } & 25 \\
\hline \multirow{2}{*}{\multicolumn{7}{|c|}{ TOTAL DE ARTIGOS REPETIDOS }} & 16 \\
\hline & & & & & & & 09 \\
\hline
\end{tabular}

Fonte: Dados da pesquisa (2020).

O Quadro 1 detalha todas as etapas referentes ao levantamento e seleção de artigos. Ao inserir as estratégias de busca de forma independente nas bases de dados, foram encontrados inicialmente 44.213 artigos. Após a aplicação dos critérios de inclusão, restaram 2.265. Depois de realizar leitura dos títulos de forma individualizada, restaram 125. Na sequência, foi realizada a leitura do resumo, obtendo-se um total de 35 artigos. Realizou-se então a leitura dos artigos na íntegra, permanecendo 25 estudos. Em seguida, houve a exclusão de 16 artigos repetidos, restando assim nove estudos que compuseram a amostra final.

\section{Resultados}

As principais características dos nove artigos que compõem a amostra final deste estudo estão sintetizados no Quadro 2. 
Quadro 2 - Caracterização dos artigos da amostra final por código do artigo, autores e ano de publicação, objetivo, tipo de estudo, cenário e cidade de realização do estudo, bases de dados de indexação dos estudos, revista de publicação. Maceió - AL, Brasil, 2020.

\begin{tabular}{|c|c|c|c|c|c|c|}
\hline$\frac{0}{0}$ & 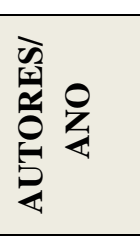 & $\sum_{\substack{0 \\
0}}^{0}$ & 될 & 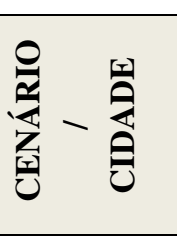 & 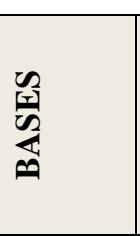 & 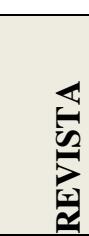 \\
\hline 1 & 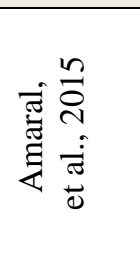 & $\begin{array}{l}\text { Identificar os fatores que podem } \\
\text { influenciar as nutrizes na } \\
\text { interrupção do aleitamento materno } \\
\text { exclusivo durante os primeiros seis } \\
\text { meses de vida do lactente. }\end{array}$ & $\begin{array}{l}\text { Qualitativo, } \\
\text { descritivo, } \\
\text { exploratório }\end{array}$ & 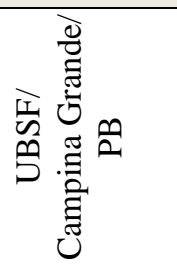 & 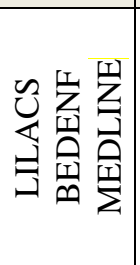 & 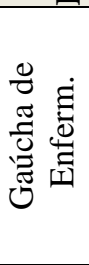 \\
\hline 2 & 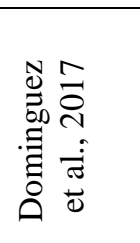 & $\begin{array}{l}\text { Conhecer, sob a ótica das } \\
\text { enfermeiras da Rede Básica de } \\
\text { Atenção à Saúde, as dificuldades } \\
\text { para o estabelecimento do } \\
\text { Aleitamento Materno. }\end{array}$ & Qualitativo & 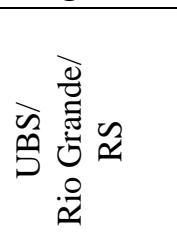 & $\underset{J}{己}$ & 章胥 \\
\hline 3 & 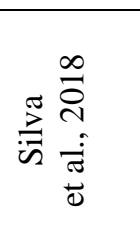 & $\begin{array}{c}\text { Identificar os empecilhos } \\
\text { apresentados pelas primíparas das } \\
\text { Unidades Básicas de Saúde, em } \\
\text { relação à amamentação exclusiva } \\
\text { dos filhos nos primeiros seis meses } \\
\text { de vida. }\end{array}$ & $\begin{array}{l}\text { Quantitativo, } \\
\text { exploratório, } \\
\text { descritivo }\end{array}$ & 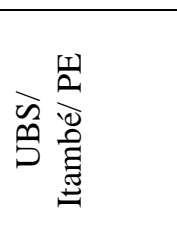 & $\underset{J}{己}$ & 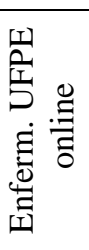 \\
\hline 4 & 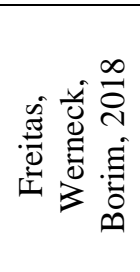 & $\begin{array}{l}\text { Conhecer a taxa de adesão ao } \\
\text { aleitamento materno exclusivo e as } \\
\text { dificuldades que levam ao desmame } \\
\text { precoce. }\end{array}$ & $\begin{array}{l}\text { Quantitativo, } \\
\text { observacional, } \\
\text { correlacional. }\end{array}$ & 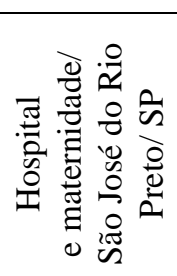 & 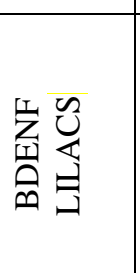 & 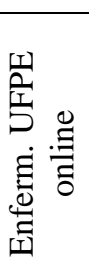 \\
\hline 5 & U & $\begin{array}{l}\text { Analisar a associação entre o tipo } \\
\text { de aleitamento e as dificuldades } \\
\text { relacionadas a essa prática entre } \\
\text { mulheres e crianças assistidas em } \\
\text { um ambulatório especializado em } \\
\text { amamentação. }\end{array}$ & $\begin{array}{l}\text { Quantitativo, } \\
\text { transversal } \\
\text { retrospectivo }\end{array}$ & 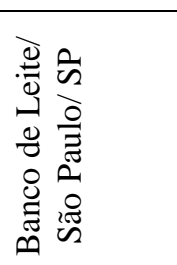 & 导 & 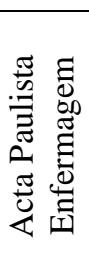 \\
\hline 6 & 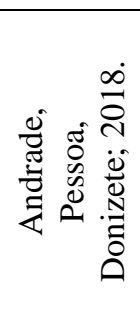 & $\begin{array}{l}\text { Investigar os fatores relacionados } \\
\text { ao desmame precoce antes dos seis } \\
\text { meses de vida. }\end{array}$ & $\begin{array}{l}\text { Quantitativo, } \\
\text { exploratório, } \\
\text { descritivo }\end{array}$ & 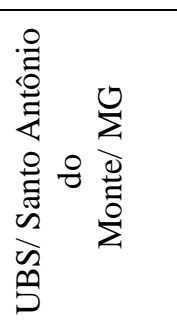 & $\underset{\Xi}{ٍ}$ & 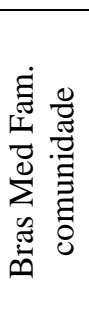 \\
\hline 7 & 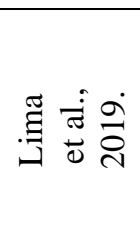 & $\begin{array}{c}\text { Estimar a prevalência de } \\
\text { aleitamento materno exclusivo de } \\
\text { prematuros na alta hospitalar, aos } \\
15 \text { e } 30 \text { dias pós-alta, e identificar } \\
\text { as alegações maternas para sua } \\
\text { interrupção. }\end{array}$ & $\begin{array}{l}\text { Quantitativo } \\
\text { transversal }\end{array}$ & 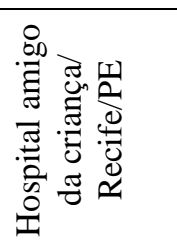 & 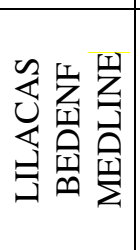 & 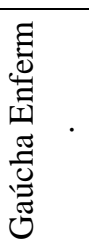 \\
\hline
\end{tabular}




\begin{tabular}{|c|c|c|c|c|c|c|}
\hline 8 & 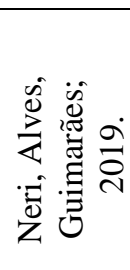 & $\begin{array}{l}\text { Verificar a prevalência de desmame } \\
\text { precoce em crianças menores de um } \\
\text { ano de idade e identificar fatores } \\
\text { sociais correlacionados com essa } \\
\text { prática. }\end{array}$ & $\begin{array}{c}\text { Quantitativo, } \\
\text { transversal, } \\
\text { descritivo }\end{array}$ & 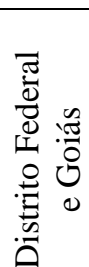 & $\begin{array}{l}U^{2} \\
\Theta\end{array}$ & $\frac{\mathscr{n}}{2}$ \\
\hline 9 & 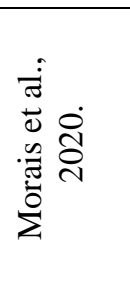 & $\begin{array}{c}\text { Conhecer a percepção das mães } \\
\text { sobre a importância do AM e } \\
\text { identificar as principais } \\
\text { dificuldades enfrentadas para a } \\
\text { prática do AM e/ou da sua } \\
\text { manutenção. }\end{array}$ & $\begin{array}{l}\text { Quantitativo, } \\
\text { descritivo, } \\
\text { transversal. }\end{array}$ & 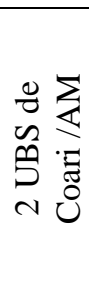 & 党 & 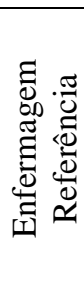 \\
\hline
\end{tabular}

Fonte: Dados da pesquisa (2020).

Dos nove artigos integrantes da amostra final do estudo, 44,44\% foram publicados em 2018, 77\% tinham abordagem quantitativa. Predominaram em 55,55\% dos estudos, como cenário, as Unidades Básicas de Saúde (UBS). As regiões Nordeste e Sudeste foram os cenários para a maioria dos estudos (33,33\% cada uma). No tocante à base de indexação, $88,88 \%$ corresponderam ao LILACS. Em relação às revistas de publicação, 22,22\% estão na Revista Gaúcha de Enfermagem e 22,22\% na Revista de Enfermagem da Universidade Federal de Pernambuco online, conforme pode ser observado no quadro 2.

No Quadro 3 estão dispostas as caraterísticas relacionadas ao número de participantes dos nove estudos da amostra final e o perfil predominante das amostras dos estudos.

A maioria dos estudos entrevistou/coletou dados de nutrizes/mães que estavam vivenciando ou vivenciaram a prática do aleitamento materno (88,88\%). A amostra mínima dos estudos foi de 14 mulheres e a máxima, de 1.608 prontuários de mulheres e crianças. A idade das mulheres entrevistadas variou entre 18 e 38 anos (Quadro 3).

Quadro 3 - Distribuição dos estudos quanto ao número de entrevistados ou amostra entrevistada, perfil sociodemográfico e principais fatores que contribuem para o desmame precoce, de acordo com os entrevistados. Maceió - AL, Brasil, 2020.

\begin{tabular}{|c|l|l|}
\hline CÓD & \multicolumn{1}{|c|}{ NÚMERO DE ENTREVISTADOS/AMOSTRA } & \multicolumn{1}{|c|}{ PERFIL PREDOMINANTE } \\
\hline 1 & $\begin{array}{l}14 \text { nutrizes no período pós-parto de um a seis meses } \\
\text { em AM. }\end{array}$ & Faixa etária de 20 a 38 anos. \\
\hline $\begin{array}{l}47 \text { enfermeiras, sendo 22 da ESF e 25 das unidades } \\
\text { tradicionais. }\end{array}$ & $\begin{array}{l}30 \text { primíparas com filhos maiores de sete meses de } \\
\text { idade, que amamentaram logo após o nascimento. }\end{array}$ & As informaçãos não estavam descritas. \\
\hline 4 & $\begin{array}{l}102 \text { mães de recém-nascidos internados no alojamento } \\
\text { conjunto. }\end{array}$ & $\begin{array}{l}\text { Faixa etária entre 30 e 35 anos, casadas } \\
(44,12 \%) .\end{array}$ \\
\hline 5 & $\begin{array}{l}1.608 \text { prontuários de crianças e mulheres no primeiro } \\
\text { atendimento no Banco de Leite. }\end{array}$ & $\begin{array}{l}\text { Idade média de 29 anos, ensino fundamental } \\
\text { completo, exercendo trabalho remunerado, } \\
\text { com companheiro. }\end{array}$ \\
\hline 6 & $\begin{array}{l}52 \text { mulheres com filhos de zero a seis meses de idade } \\
\text { de vida que não estavam mais em AME. }\end{array}$ & $\begin{array}{l}\text { Faixa etária de 18 a 23 anos, branca (67\%), } \\
\text { ensino médio completo (37\%), emprego } \\
\text { formal (48\%), casadas (54\%). }\end{array}$ \\
\hline 7 & $\begin{array}{l}108 \text { prematuros nascidos nos referidos hospitais e suas } \\
\text { respectivas mães, totalizando 94. }\end{array}$ & $\begin{array}{l}\text { 58\% eram bebês do sexo feminino, 84,3\% } \\
\text { com idade gestacional de 32 a 36 semanas. }\end{array}$ \\
\hline 8 & $\begin{array}{l}235 \text { mães de crianças entre zero e 12 meses de idade } \\
\text { de ambos os sexos. }\end{array}$ & $\begin{array}{l}\text { Faixa etária de 20 a 30 anos (57,7\%), ensino } \\
\text { médio completo (44,4\%), empregadas } \\
\text { (52,25\%), casadas (56,6\%). }\end{array}$ \\
\hline
\end{tabular}




\begin{tabular}{|c|l|l|}
\hline 9 & $\begin{array}{l}50 \text { mães de crianças registradas no programa de } \\
\text { crescimento e desenvolvimento da UBS de Coari. }\end{array}$ & $\begin{array}{l}\text { Idade superior a 18 anos (70\%), ensino médio } \\
\text { incompleto (40\%), em união estável (56\%), } \\
\text { donas de casa (34\%) e multíparas (58\%). }\end{array}$ \\
\hline
\end{tabular}

Fonte: Dados da pesquisa (2020).

O Gráfico 1 detalha os motivos para o desmame precoce mencionados com maior frequência nos estudos da amostra.

Gráfico 1 - Representação gráfica dos principais motivos para o desmame precoce de acordo com a frequência citada nos estudos da amostra estudada, Maceió - AL, Brasil, 2020.

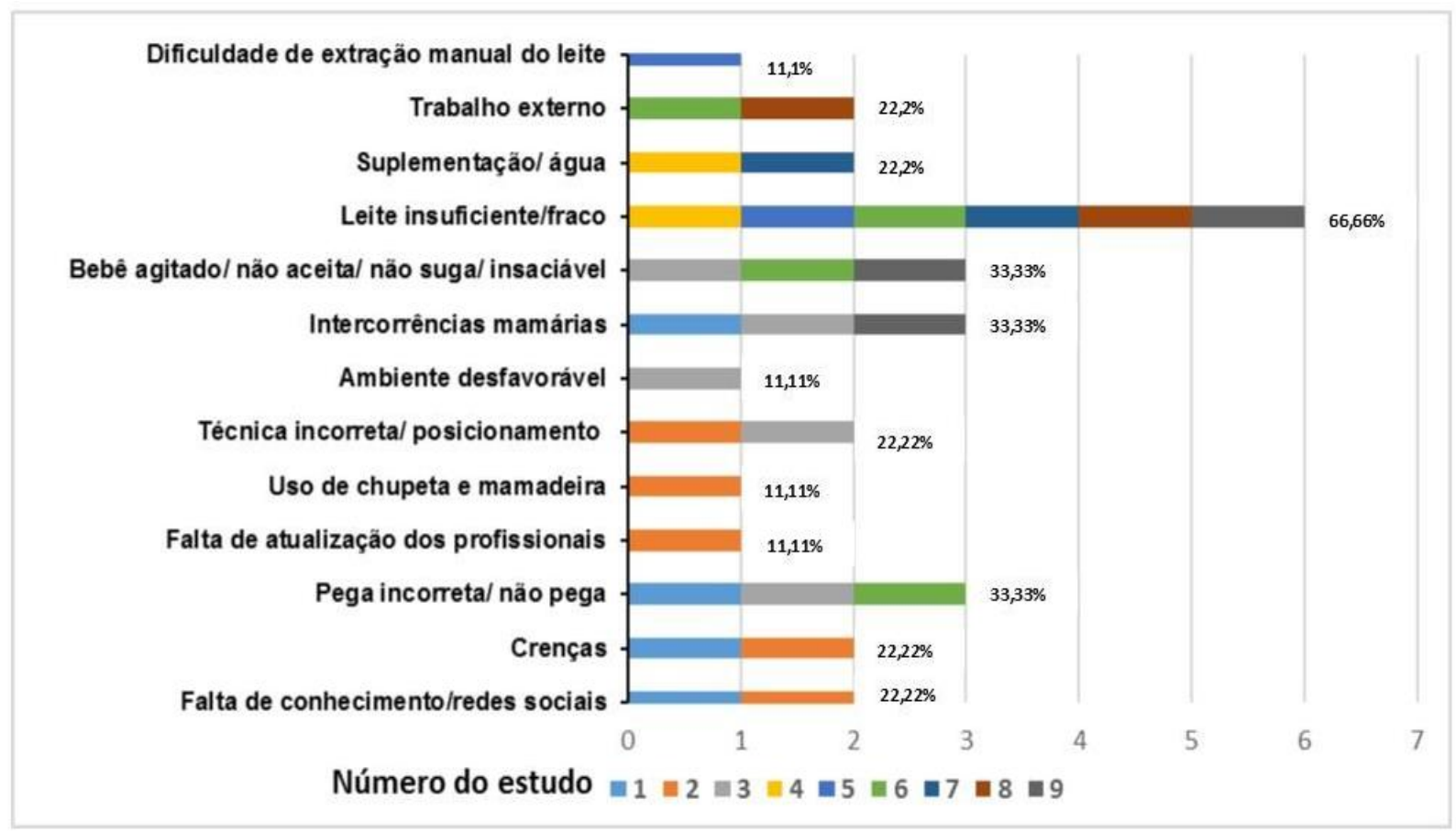

Fonte: Dados da pesquisa (2020).

Conforme pode ser verificado no Gráfico 1, os motivos para o desmame precoce que apareceram com maior frequência nos estudos foram: a percepção que as nutrizes tinham que o leite era fraco e/ou insuficiente, presente em 66,66\% dos estudos analisados. Em seguida, em 33,33\% dos estudos foram citados como fatores que interferem no desmame precoce o bebê agitado, que não aceita mamar, não suga ou era insaciável; também em 33,33\% foram citadas as intercorrências mamárias; e com mesma frequência $(33,33 \%)$, a pega incorreta ou não conseguir fazer a pega.

\section{Discussão}

Apesar de o aleitamento materno exclusivo ser recomendado pela OMS, ainda é pouco realizado (Amaral et. al., 2015). Nos estudos analisados, os principais fatores que levaram à interrupção da amamentação foram a percepção da mulher de que tem leite fraco/insuficiente, as intercorrências mamárias e a pega incorreta.

A percepção de o "leite fraco" influenciar negativamente no processo da amamentação passa a existir na vida da mulher devido à insegurança materna, reforçada pelo contexto familiar e pelo choro constante do bebê. Isso faz acreditar que o bebê "chora de fome". Oferecem-se a ele mamadeira e leites de fórmulas, por se acreditar que seu leite não o sustém (Amaral et. al., 2015).

Fatores como ansiedade, estresse e cansaço podem influenciar na produção do leite e consequentemente fazer com que 
a mulher chegue a pensar que seu leite é insuficiente para alimentar o bebê. É necessário que os profissionais de saúde estejam atentos para promover e incentivar a aquisição de conhecimentos/retirada de dúvidas acerca da amamentação e fornecer o apoio a essa gestante, para que ela consiga diminuir o estresse e o cansaço nesse período (Freitas; Borim; Werneck, 2018).

Lima e colaboradores (2019) destacam que os primeiros trinta dias após a alta hospitalar são considerados essenciais para que haja uma interação no ciclo mãe-bebê-família. É necessário que a equipe de saúde esteja qualificada para melhor atender essa mulher, seu bebê e sua família, prestando uma assistência que inclua a promoção do AME.

Compete ao enfermeiro observar os fatores emocionais e sociais da mulher durante os atendimentos, isso porque o desmame pode estar associado às crenças que a mulher tem acerca da amamentação. O profissional deve levar em consideração toda a bagagem cultural que a mulher possui e deve se dispor a compartilhar seus conhecimentos técnicos e científicos por meio da educação em saúde, bem como encorajá-la a vencer os obstáculos que podem surgir durante o AME (Almeida; Luz; Ued, 2015).

Outros fatores relacionados ao desmame precoce nas publicações analisadas foram a pega incorreta e as intercorrências mamárias. Quando a pega está incorreta, além de o bebê não conseguir mamar de forma efetiva, isso favorece a ocorrência de outros fatores negativos, como, por exemplo, o surgimento de fissuras mamilares, que provocam dor e levam à desistência da mulher do processo de aleitamento (Carreiro et al., 2018).

As lesões mamilares ocorrem devido ao posicionamento e à pega incorreta do bebê no ato da amamentação. Também favorecem o ingurgitamento mamário e as mastites. Esses quadros geralmente têm a dor como sintoma comum, o que pode provocar na mulher sentimentos como angústia, aflição e irritabilidade, levando-a ao abandono da prática do AME (Moraes et. al., 2020).

Há, ainda, um quantitativo alto de mulheres que interrompem a prática da amamentação devido a intercorrências mamárias. Andrade e colaboradores (2018) destacam a importância da atuação do enfermeiro. Em um único estudo realizado com profissionais enfermeiros, observou-se que existe um despreparo por parte desses profissionais quanto às orientações corretas no tocante à prática da amamentação. Torna-se necessária a discussão dos aspectos que envolvam a amamentação, promovendo entre os profissionais uma reflexão dos fatores que levam ao desmame precoce (Dominguez, 2017).

Neri e colaboradores (2019) orientam sobre a importância da intensificação do enfermeiro nas orientações realizadas a fim de solucionar os empecilhos que conduzem ao desmame precoce e ressaltar os motivos que podem tornar essa prática prazerosa, e assim transmitir a essa nutriz a certeza de que amamentar é um ato tranquilo e prazeroso.

\section{Conclusão}

O presente estudo respondeu à questão norteadora descrevendo os fatores que contribuem para o desmame precoce. Nos estudos analisados, múltiplos fatores interferiram na prática da amamentação e favoreceram o desmame precoce. Entre eles, destacam-se o leite insuficiente/fraco, as intercorrências mamárias e a pega incorreta.

A identificação desses fatores que levam ao desmame precoce é imprescindível à promoção de intervenções mais efetivas a fim de minimizar os empecilhos que levam ao desmame precoce. Mesmo as mulheres que receberam orientações durante o pré-natal podem deparar-se com essas barreiras. É fundamental que os profissionais de saúde e gestores possam discutir esses fatores de forma ampliada e tracem estratégias favoráveis à melhora da adesão ao AME.

É premente a realização de estudos de intervenção voltados a profissionais de saúde a fim de identificar as dificuldades na prestação da assistência às mulheres com dificuldades em relação ao aleitamento materno e na implementação de intervenções educacionais voltadas à resolução das principais lacunas apontadas. Na atualidade, são citadas na literatura científica muitas tecnologias em saúde direcionadas a solucionar os principais problemas que impedem o aleitamento materno exclusivo, porém ainda há poucos estudos que testam a sua efetividade. Muitas dessas tecnologias não estão disponíveis nos serviços de saúde. 
Nesse sentido, ao vislumbrar os principais fatores que impedem o aleitamento materno exclusivo, faz-se necessário pesquisar as soluções disponíveis e adotá-las em vários contextos, com ênfase no uso de tecnologias educacionais.

\section{Referências}

Algarves, T. R., de Sousa Julião, A. M., \& Costa, H. M. (2015). Aleitamento materno: influência de mitos e crenças no desmame precoce/breastfeeding: myths and beliefs influence in early weaning. Saúde em Foco, 2(1), 151-167.

Almeida, J. M. D., Luz, S. D. A. B., \& Ued, F. D. V. (2015). Apoio ao aleitamento materno pelos profissionais de saúde: revisão integrativa da literatura. Revista Paulista de Pediatria, 33(3), 355-362.

Andrade, H. S., Pessoa, R. A., \& Donizete, L. C. V. (2018). Fatores relacionados ao desmame precoce do aleitamento materno. Revista Brasileira de Medicina de Família e Comunidade, 13(40), 1-11.

Amaral, L. J. X., Sales, S. D. S., Carvalho, D. P. D. S. R. P., Cruz, G. K. P., Azevedo, I. C. D., \& Ferreira Júnior, M. A. (2015). Fatores que influenciam na interrupção do aleitamento materno exclusivo em nutrizes. Revista gaúcha de enfermagem, 36(SPE), 127-134.

Araújo, J. P., Almeida, J. L. S., Souto, C. M. R. M., de OLIVEIRA, A. E. A., \& Sudério, M. A. R. P. (2013). Desmame precoce e suas causas: experiência na atenção básica de Campina Grande-PB. Revista da Universidade Vale do Rio Verde, 11(2), 146-155.

Barbosa, L. N., Santos, N. C. D., Moraes, M. A. M. D., Rizzardi, S. D., \& Corrêa, E. D. C. (2015). Prevalência de práticas educativas acerca do aleitamento materno exclusivo (AME) em Cuiabá-MT. Escola Anna Nery, 19(1), 147-153.

Carreiro, J. D. A., Francisco, A. A., Abrão, A. C. F. D. V., Marcacine, K. O., Abuchaim, E. D. S. V., \& Coca, K. P. (2018). Dificuldades relacionadas ao aleitamento materno: análise de um serviço especializado em amamentação. Acta Paul Enferm., 31(4), 430-438.

Dominguez, C. C., da Costa Kerber, N. P., Rockembach, J. V., Susin, L. R. O., Pinheiro, T. M., \& da Fonseca Rodrigues, E. (2017). Dificuldades no estabelecimento da amamentação: visão das enfermeiras atuantes nas unidades básicas de saúde. Revista Enfermagem UERJ, $25,14448$.

Freitas, M. G. D., Werneck, A. L., \& Borim, B. C. (2018). Aleitamento materno exclusivo: adesão e dificuldades. Rev. Enferm. UFPE on line, $2301-2307$.

Lima, A. P. E., Castral, T. C., Leal, L. P., Javorski, M., Sette, G. C. S., Scochi, C. G. S., \& de Vasconcelos, M. G. L. (2019). Aleitamento materno exclusivo de prematuros e motivos para sua interrupção no primeiro mês pós-alta hospitalar. Revista Gaúcha de Enfermagem, 40.

Ministério da Saúde (BR), Secretaria de Atenção à Saúde. Saúde da Criança: aleitamento materno e alimentação complementar. Brasília (DF); 2015.

Moraes, I. C., Sena, N. L., Oliveira, H. K. F., Albuquerque, F. H. S., Rolim, K. M. C., Fernandes, H. I. V. M., \& Silva, N. C. (2020). Percepção sobre a importância do aleitamento materno pelas mães e dificuldades enfrentadas no processo de amamentação. Revista de Enfermagem Referência, serV(2), e19065.

Neri, V. F., Alves, A. L. L., \& Guimarães, L. C. (2019). Prevalência de desmame precoce e fatores relacionados em crianças do Distrito Federal e entorno. Revista de Divulgação Científica Sena Aires, 8(4), 451-459.

Organização das Nações Unidas. Política de aleitamento materno no Brasil é referência mundial, diz OMS. 2016.

Organização Pan-Americana de Saúde. Aleitamento materno nos primeiros anos de vida salvaria mais de 820 mil crianças menores de cinco anos em todo o mundo. 2018.

Silva, A. M. D., Santos, M. C. S. D., Silva, S. R. D. M., Ferreira, F. Â., Freitas, R. D. S. C., Santos, R. E. A. D., \& Gouveia, M. T. (2018). Aleitamento materno exclusivo: empecilhos apresentados por primíparas. Rev. Enferm. UFPE on line, 3205-3211. 
Research, Society and Development, v. 10, n. 1, e0910111218, 2021

(CC BY 4.0) | ISSN 2525-3409 | DOI: http://dx.doi.org/10.33448/rsd-v10i1.11218

Sousa, L. M. M., Vieira, C. M. A. M., Severino, S. S. P., \& Antunes, A. V. (2017). A metodologia de revisão integrativa da literatura em enfermagem. Rev. investigação. enferm. 17-26.

Sousa, M. S., Aquino, P. D. S., Aquino, C. B. D. Q., Penha, J. C., \& Pinheiro, A. K. B. (2015). Aleitamento materno e os determinantes do desmame precoce. Rev. enferm. UFPI, 19-25.

Souza, M. T. D., Silva, M. D. D., \& Carvalho, R. D. (2010). Revisão integrativa: o que é e como fazer. Einstein (São Paulo), 8(1), 102-106. 